\title{
Condutividade térmica estimada a partir da composição química de granitos porfiríticos do Domínio Rio Grande do Norte, NE do Brasil
}

Tércia Jaíres de Oliveira Silva*, UFRN; Diego Tavares de França, UFRN; Antonio Carlos Galindo, UFRN; Fernando Antônio Pessoa Lira Lins, UFRN

Copyright 2014, SBGf - Sociedade Brasileira de Geofísica

Este texto foi preparado para a apresentação no VI Simpósio Brasileiro de Geofísica, Porto Alegre, 14 a 16 de outubro de 2014. Seu conteúdo foi revisado pelo Comite Técnico do VI SimBGf, mas não necessariamente representa a opinião da SBGf ou de seus associados. É proibida a reprodução total ou parcial deste material para propósitos comerciais sem prévia autorização da SBGf.

\section{Abstract}

This work was elaborated using 34 samples from porphyritic granites of the Rio Grande do Norte Domain (Borborema Province, NE Brazil). With the geochemical data and density of the samples, the thermal conductivity was estimated using an empirical relationship presented by Horai e Baldridge (1972) for equigranular igneous rocks. In this work the empirical relationship was tested on porphyritic granites and compared with the thermal conductivity obtained experimentally.

\section{Introdução}

Em rochas ígneas os principais fatores que influenciam a condutividade térmica são a mineralogia, textura, anisotropia e densidade (Schon, 2004). Entre os minerais formadores destas rochas, 0 quartzo apresenta relativamente a maior condutividade térmica. Segundo Figueiredo et. al. (2008), rochas com proporções maiores que $20 \%$ de quartzo e textura porfirítica tendem a favorecer a condução de calor quando comparadas com aquelas com menos de $20 \%$ de quartzo e textura fina/media.

As amostras analisadas são de granitos porfiríticos do Domínio Rio Grande do Norte (DRN) da Província Borborema. Segundo Nascimento et. al. (2008), esses granitos pertencem à Suíte Cálcio-alcalina de alto $\mathrm{K}$ Porfirítica que pode ocorrer como batólitos isolados ou associados a outros tipos de rochas, em especial àquelas da suíte Shoshonítica. Estas rochas foram caracterizados petrograficamente como sienogranitos, monzogranitos, granodioritos e quartzo sienitos, que texturalmente apresentam fenocristais de K-feldspato. A densidade média dos granitos porfiríticos estudados foi de 2,68 $\mathrm{g} / \mathrm{cm}^{3}$.

O objetivo deste trabalho é estimar a condutividade térmica para rochas porfiríticas a partir da relação empírica proposta por Horai e Baldridge (1972). A condutividade térmica estimada será comparada com a condutividade térmica experimental das 34 amostras. Este resultado possibilita a obtenção da condutividade térmica de rochas porfiríticas a partir da geoquímica, podendo auxiliar numa análise preliminar sobre 0 comportamento térmico dos granitóides.

\section{Metodologia}

As medidas de condutividade térmica em laboratório foram realizadas com o equipamento Quickline ${ }^{\text {TM }} 30$. Utilizou-se o regime dinâmico baseado no método transiente por meio de uma fonte de calor planar com intervalo de leitura de $2,00-6,00 \mathrm{~W} / \mathrm{m}$.K por ser o intervalo mais adequado ao tipo de rocha estudada. Foram realizadas cinco medidas na face polida de cada amostra, utilizando-se a média das medidas para este estudo (figura 1). O referido equipamento apresenta uma margem de erro experimental em torno de $10 \%$.

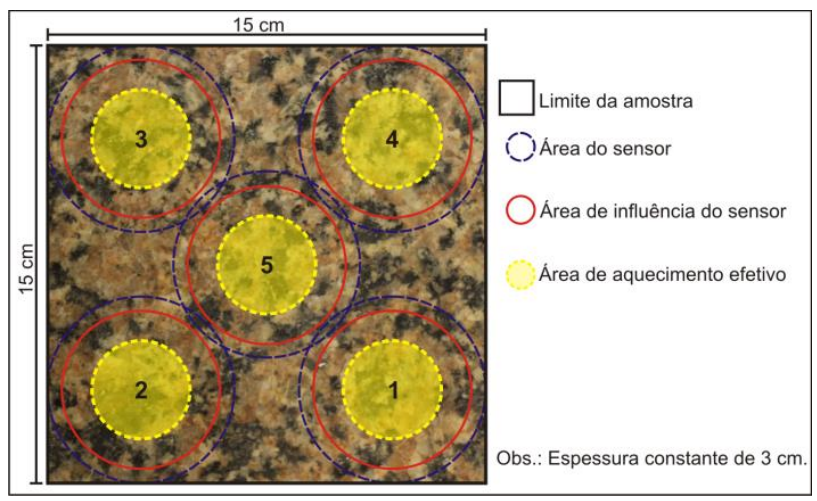

Figura 1 - Procedimento para aquisição dos dados de condutividade térmica.

A condutividade térmica estimada foi obtida a partir de uma relação empírica descrita por Horai e Baldridge (1972), onde são considerados o peso atômico médio $M$ e a densidade $D$ de cada amostra.

$$
k=a+b D
$$

Onde:

$\mathrm{k}=$ condutividade térmica (mcal $\cdot \mathrm{cm}^{-1} \cdot \mathrm{s}^{-1} \cdot{ }^{\circ} \mathrm{C}^{-1}$ ),

$\mathrm{a}=39,0-3,25 \mathrm{M}\left(\mathrm{mcal} \cdot \mathrm{cm}^{-1} \cdot \mathrm{s}^{-1} \cdot{ }^{\circ} \mathrm{C}^{-1}\right)$,

$\mathrm{b}=13,0\left(\mathrm{mcal} \cdot \mathrm{cm}^{-1} \cdot \mathrm{s}^{-1} \cdot{ }^{\circ} \mathrm{C}^{-3}\right) /\left(\mathrm{g} \cdot \mathrm{cm}^{-3}\right)$

Os resultados obtidos de condutividade térmica foram convertido para $\mathrm{W} / \mathrm{m} . \mathrm{K}$.

Para as medidas de densidade foram confeccionados três cubos de cada amostra com dimensões $3 \mathrm{~cm} \times 3 \mathrm{~cm} \times$ $3 \mathrm{~cm}$. Inicialmente todas as amostras foram secadas na estufa a uma temperatura de $50^{\circ} \mathrm{C}$, para que toda a água fosse retirada dos poros. Após serem retiradas da estufa foi realizada a primeira medida que consiste em medir a massa da rocha com os poros preenchidos por ar, sendo obtido o peso seco $\left(P_{s}\right)$. Para realizar a segunda e a terceira medida os cubos foram colocados em uma bandeja e cobertos por água ao longo de três etapas, 
com intervalos de $12 \mathrm{hs}$, até que fossem completamente submersos para que os poros fossem totalmente preenchidos num período de 48hs. A segunda medida ( $\left.P_{\text {sub }}\right)$ é realizada com o cubo saturado em água submerso em um béquer contendo água destilada, a terceira medida é realizada com o cubo saturado em água, no ar, fornecendo o peso saturado $\left(\mathrm{P}_{\text {sat }}\right)$. $\mathrm{A}$ densidade é obtida em $\mathrm{g} / \mathrm{cm}^{3}$ a partir da seguinte equação:

$$
\rho=\frac{P_{\text {seco }}}{P_{\text {sat }}-P_{\text {sub }}} \rho_{\text {água }}
$$

Equação 1 - Relação entre os pesos medidos para a obtenção da densidade da amostra.

\section{Resultados}

Os dados utilizados e resultados obtidos são observados na tabela 1, onde são apresentados a densidade $D$, o peso atômico médio $M$, a condutividade térmica medida $(\mathrm{K})$, a condutividade térmica estimada (Ki) e erro relativo percentual.

\begin{tabular}{|c|c|c|c|c|c|}
\hline Litologia & $D\left(\mathrm{~g} / \mathrm{cm}^{3}\right)$ & $M$ & $\mathrm{~K}(\mathrm{~W} / \mathrm{m} . \mathrm{K})$ & $\mathrm{Ki}(\mathrm{W} / \mathrm{m} . \mathrm{K})$ & $\Delta \mathrm{Ki}-\mathrm{K} / \mathrm{K}(\%)$ \\
\hline Granodiorito & 2,70 & 21,03 & 2,48 & 2,39 & $-3,78$ \\
\hline Granodiorito & 2,77 & 21,29 & 2,12 & 2,42 & 14,27 \\
\hline Granodiorito & 2,70 & 20,97 & 2,46 & 2,51 & 2,18 \\
\hline Monzogranito & 2,68 & 21,01 & 2,86 & 2,31 & $-19,06$ \\
\hline Monzogranito & 2,66 & 20,69 & 2,93 & 2,68 & $-8,63$ \\
\hline Monzogranito & 2,69 & 21,08 & 2,72 & 2,27 & $-16,42$ \\
\hline Monzogranito & 2,65 & 20,92 & 2,21 & 2,30 & 4,23 \\
\hline Monzogranito & 2,63 & 20,93 & 2,34 & 2,18 & $-6,64$ \\
\hline Monzogranito & 2,70 & 21,03 & 2,54 & 2,41 & $-5,24$ \\
\hline Monzogranito & 2,66 & 20,93 & 2,26 & 2,31 & 2,04 \\
\hline Monzogranito & 2,63 & 20,98 & 2,55 & 2,10 & $-17,71$ \\
\hline Monzogranito & 2,72 & 21,18 & 2,43 & 2,33 & $-3,91$ \\
\hline Monzogranito & 2,72 & 21,29 & 2,28 & 2,17 & $-4,73$ \\
\hline Monzogranito & 2,63 & 20,77 & 2,99 & 2,40 & $-19,76$ \\
\hline Monzogranito & 2,67 & 20,86 & 2,36 & 2,47 & 4,68 \\
\hline Monzogranito & 2,67 & 20,95 & 2,34 & 2,38 & 1,79 \\
\hline Monzogranito & 2,65 & 20,86 & 2,76 & 2,35 & $-15,03$ \\
\hline Monzogranito & 2,66 & 20,80 & 2,92 & 2,49 & $-14,76$ \\
\hline Monzogranito & 2,60 & 20,75 & 2,79 & 2,26 & $-18,99$ \\
\hline Monzogranito & 2,66 & 20,84 & 2,34 & 2,48 & 5,81 \\
\hline Monzogranito & 2,72 & 20,96 & 2,54 & 2,63 & 3,60 \\
\hline Monzogranito & 2,64 & 20,94 & 2,23 & 2,23 & $-0,13$ \\
\hline Monzogranito & 2,74 & 21,09 & 2,16 & 2,56 & 18,66 \\
\hline Monzogranito & 2,70 & 21,21 & 2,43 & 2,15 & $-11,56$ \\
\hline Quartzo sienito & 2,71 & 21,12 & 2,13 & 2,36 & 11,15 \\
\hline Quartzo sienito & 2,72 & 21,38 & 2,20 & 2,04 & $-7,05$ \\
\hline Quartzo sienito & 2,68 & 20,90 & 2,65 & 2,49 & $-5,92$ \\
\hline Sienogranito & 2,62 & 20,89 & 2,67 & 2,18 & $-18,19$ \\
\hline Sienogranito & 2,68 & 21,11 & 2,56 & 2,19 & $-14,49$ \\
\hline Sienogranito & 2,65 & 20,94 & 2,78 & 2,25 & $-18,96$ \\
\hline Sienogranito & 2,65 & 20,83 & 2,91 & 2,41 & $-17,15$ \\
\hline Sienogranito & 2,66 & 20,86 & 2,71 & 2,42 & $-10,69$ \\
\hline Sienogranito & 2,73 & 20,87 & 2,43 & 2,77 & 13,98 \\
\hline Sienogranito & 2,66 & 20,81 & 2,72 & 2,52 & $-7,38$ \\
\hline
\end{tabular}

Tabela 1 - Dados utilizados e resultado comparativo entre as condutividades térmicas medidas e estimadas.
$\mathrm{Na}$ figura 2, os valores da condutividade térmica estimada (Ki) são comparados com a condutividade térmica medida $(K)$ diretamente nas amostras. Observase que 24 amostras do grupo apresentaram erro relativo percentual menor que $15 \%$ e as outras 10 amostras apresentam erro relativo percentual menor que $20 \%$. Neste estudo o erro relativo percentual utilizado como referência foi de $15 \%$, sendo levados em conta que $10 \%$ do erro experimental do equipamento Quickline ${ }^{\text {TM }} 30$ e $3 \%$ na precisão da medida, os valores obtidos são validos como valores médios para as litologias estudadas. Desta forma a extensão dos cálculos a outros granitos de composição, textura e estrutura similar podem ser considerados como coerentes para determinação da sua condutividade térmica.

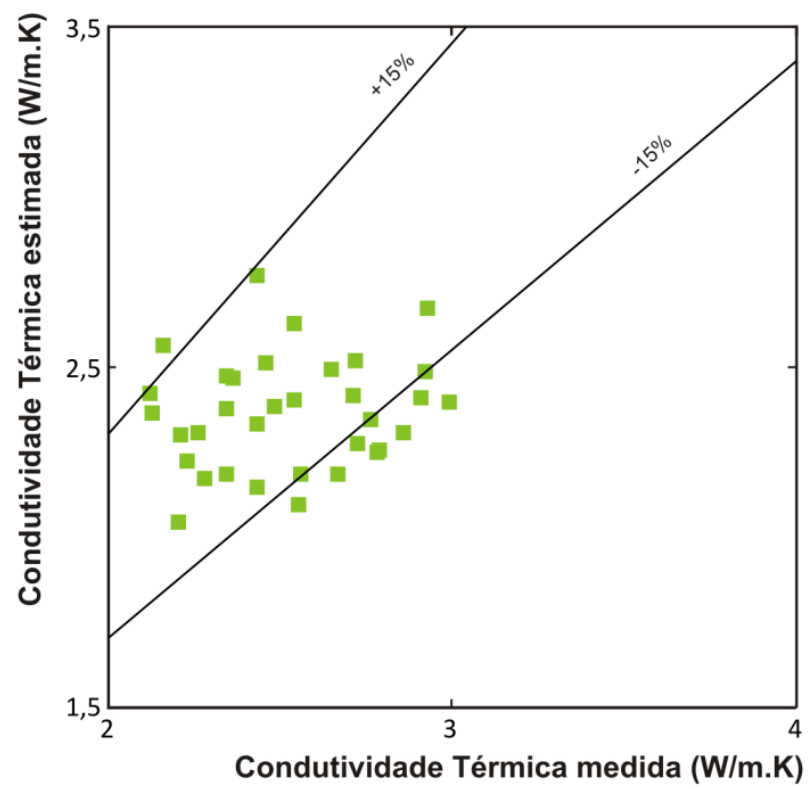

Figura 2 - Comparação entre a condutividade térmica estimada e a condutividade térmica medida.

\section{Discussão e Conclusões}

Os resultados obtidos de condutividade térmica estimada a partir da relação empírica apresentada por Horai e Baldridge (1972) para rochas ígneas porfiríticas mostraram-se bastante satisfatórios.

Segundo Horai e Baldridge (1972), a condutividade térmica estimada para rochas a partir da densidade e do peso atômico médio é mais sensível a variações de densidade para um peso atômico médio constante. Para as rochas estudadas a densidade média foi de 2,68 $\mathrm{g} / \mathrm{cm}^{3}$. Este comportamento é atribuído à relação entre a densidade e a condutividade térmica das rochas, onde rochas ricas em sílica tendem a apresentar altos valores de condutividade térmica e baixos valores de densidade.

A análise dos resultados observados nesse estudo mostra que a metodologia utilizada pode ser aplicada para rochas macroscopicamente anisotrópicas como os granitos porfiríticos do Domínio Rio Grande do Norte, 
servindo como parâmetro preliminar acerca do comportamento térmico destas rochas.

\section{Agradecimentos}

Os autores agradecem à PETROBRAS/UFRN pelo financiamento do projeto "Parametrização de Afloramentos do Embasamento Cristalino da Bacia do Ceará e Interiores do Trend Cariri-Potiguar para Estudos de Condutividade Térmica: Um Tema em Continuidade", que forneceu os dados utilizados neste trabalho.

Ao Programa de Pós Graduação em Geodinâmica e Geofísica da Universidade Federal do Rio Grande do Norte.

$\mathrm{E}$ ao $\mathrm{CNPq}$ pela concessão da bolsa de mestrado à autora Tércia Jaíres de O. Silva.

\section{Referências}

Figueiredo, E.R.H, Galindo, A.C., Moreira, J.A.M., Lins, F.A.P.L., 2008. Condutividade térmica em rochas silicáticas cristalinas, com ênfase a rochas graníticas da Província Borborema, NE do Brasil, e sua correlação com parâmetros petrográficos e texturais. Rev. Bras. Geof., 26(3): 293-307.

Horai, K. and Baldridge, S., 1972. Thermal conductivity of nineteen igneous rocks, II Estimation of the thermal conductivity of rock from the mineral and chemical compositions. Phys. Earth Planet. Interiors 5, 157-166.

Nascimento, M. A. L., Medeiros, V. C., Galindo, A. C., 2008. Magmatismo ediacarano a cambriano no Domínio Rio Grande do Norte, Província Borborema, NE do brasil. Revista Estudos Geológicos v.18(1).

Schön, J. H. 2004. Physical Properties of Rocks: Fundamentals and Principles of Petrophysics (Handbook of Petroleum Exploration and Production). Volume 8. Ed. ELSEVIER. Cap. 8. 